\title{
Ações, Rastros e Controvérsias Online/ Offline: possibilidades metodológicas a partir da Teoria Ator- rede
}

\section{Actions, Traces and Controversies Online/ Offline: possibilities methodological from Actor-Network Theory}

\section{Acciones, Rastros y Controversias on-line $y$ off-line: posibilidades metodológicas de la Teoría del Actor-Red}

\author{
Ana Paula Pereira Coelho* \\ Universidade Federal do Maranhão - UFMA, São Luís, Maranhão, Brasil \\ Patrícia Azambuja** \\ Universidade Federal do Maranhão - UFMA, São Luís, Maranhão, Brasil
}

\begin{abstract}
RESUMO
O processo de convergência midiática nos oferece um campo vasto e complexo de práticas cotidianas e comportamentais. Ações virtuais, invariavelmente, trazem à tona dimensões que envolvem, em um primeiro momento, ações simples e conversações em rede. A partir das quais, um olhar mais cuidadoso, revela com igual força condições tecnológicas, materiais, visibilidade social, questões humanas, culturais, políticas, entre outras - com curiosa fluidez para algumas situações que transitam livremente entre os espaços online e offline, entre o público e o privado, entre meios interpessoais e massivos etc. A partir desse cenário, e utilizando um caso específico como ponto de partida, propomos a produção de um pequeno mapa de conexões, empregando a Teoria Ator Rede (TAR) como possibilidade metodológica. A partir de uma escrita etnográfica (em contexto virtual) buscamos rastrear vínculos e estabilizar uma rede que nos permitisse compreender, mesmo que parcialmente, os múltiplos fluxos e associações proporcionadas pelos dispositivos de comunicação (digitais e/ou convencionais).
\end{abstract}

Palavras-Chave: redes sociais, sociotécnica, teoria ator-rede, metodologia.

\section{ABSTRACT}

The media convergence process offers a wide area and everyday practices and behavioral complex. Virtual actions invariably show up dimensions involved, at first, simple actions and conversations in the network. However, that view reveals, among other things, technological conditions, social visibility, human, cultural, political affairs, etc. There is a curious fluidity to some events which pass freely between on-line and off-line spaces, between public and private spaces, and also between interpersonal and mass media space etc. At this stage and using a specific area as a starting point, we propose the production of a small connection map. Using the Actor-network 
Theory, often abbreviated as ANT, as a methodological possibility. From an ethnographic writing (in virtual context) we look for tracing linkage and stabilize a network that allows us to understand, even partially, the multiple flows and associations provided by the communications tools (digital or conventional).

Keywords: social networks, sociotechnics, actor network theory, methodology.

\begin{abstract}
RESUMEN
El proceso de convergencia mediático nos ofrece un campo amplio y complejo de prácticas cotidianas y de comportamientos. Las acciones virtuales, invariablemente, revelan dimensiones que envuelven, en un primer momento, acciones simples y conversaciones en la red. Sin embargo, observando cuidadosamente muestra, entre otras cosas, condiciones tecnológicas, visibilidad social, cuestiones humanas, culturales, políticas, etc. Existe una fluidez curiosa para algunos eventos que transitan libremente entre diversos espacios, ya sean estos: on-line y off-line, público y privado, medios interpersonales y masivos etc. A partir de este escenario y utilizando un campo específico como punto de partida, proponemos la producción de un pequeño mapa de conexiones. Para ello, utilizamos la Teoría del ActorRed, de sus siglas en inglés ANT, como una posible metodología. A partir de una escritura etnográfica (en contexto virtual) buscamos rastrear los vínculos y estabilizar una red que nos ha permitido comprender, aunque sea parcialmente, los múltiples flujos y asociaciones proporcionadas por las herramientas de comunicación (digital o convencional).
\end{abstract}

Palabras-Clave: redes sociales, sociotechnics, teoría del actor-red, metodología.

\title{
1 I ntrodução
}

Reportagem recente ${ }^{1}$, baseada em dados disponibilizados pela ONG Safernet Brasil 2, afirma que o número de vítimas do compartilhamento de fotos íntimas pela internet dobrou nos últimos dois anos no país: de 42 atendimentos, no ano 2012, para 101 em 2013. Algumas expressões surgem no sentido de definir comportamentos que evidenciam novas maneiras de expressar sexualidade entre os jovens, e o nude selfie, ou selfie com nudez, marca essa nova forma de comunicação por imagem, que viabiliza muitas vezes uma prova de cumplicidade entre parceiros. No entanto, o que alguns desses indivíduos nem parecem desconfiar, é que essas fotos, uma vez disponibilizadas no espaço online, passam a ocupar um campo de dinâmica própria, e aparentemente sem limites, sem controle. Reverberando inclusive situações e desdobramentos nos espaços offline.

O processo da comunicação passa hoje por situações de extrema complexidade decorrentes das relações híbridas implicadas pela "cultura da convergência de mídias" - resultado do atravessamento entre diferentes meios de produção, distribuição e consumo de informação e entretenimento. Este conceito introduzido por Marsha 
Kinder (1991) e Henry Jenkins (2008) tem como prerrogativa a ampliação dos conteúdos para além da simples distribuição multiplataforma. Nesse sentido, somos levados a compreender que o desenvolvimento tecnológico não possa ser compreendido integralmente, quando apartado dos seus contextos socioculturais e materiais de uso.

Assim, definimos nosso ponto de partida para esta investigação: compreender as interconexões fluidas (muitas vezes, até mesmo nebulosas para alguns) das fronteiras online e offline. Isto é, ações observadas no mundo das trocas virtuais que transitam de forma aparentemente espontânea e, até certo ponto, descentralizada por entre os espaços materialmente percebidos. O que, se por um lado, configuram movimentos e consequências nem sequer percebidas por alguns usuários, por outro, acabam servindo como embriões estruturantes e conscientes para ações efetivas e mudanças significativas em toda sociedade. E vale destacar: nem sempre apenas para os envolvidos diretos nas tramas de conexões.

Partindo da ideia de possível fluidez entre campos aparentemente diversos - virtual e real - e por isso mesmo, também, contraditória, pareceu-nos urgente uma escolha metodológica compatível com o campo híbrido e em contínuo movimento, como nos parece o da cultura da convergência. Tema já discutido, pelo viés da comunicação, em trabalhos anteriores: Lemos (2013a, 2013b), Azambuja (2012), Azambuja e Monteiro (2012), Lopes (2011), Santaella \& Lemos (2010), entre outros. A professora Maria Immacolata Vassallo de Lopes (2011) contextualiza sua preocupação metodológica a partir de situações complexas vinculadas à multiplicação das telas de acesso e modos de uso dos diferentes indivíduos envolvidos no processo. Questões compatíveis com universo que nos propomos a observar, que de tão complexo e heterogêneo nos perguntamos, já de início, por onde começar.

Escolhemos, portanto, utilizar como referência inicial a Teoria Atorrede (TAR), e escolhemos seguir o caminho das controvérsias (Latour, 2005; Lemos, 2013b). Como, para Bruno Latour (1994, 2000, 2005), o social só se configura a partir das conexões rastreáveis, definimos, portanto, como ponto de partida o Caso Marie 3 e passamos a rastrear conexões ao observar suas principais controvérsias. "A sociedade - considerada pela TAR em seu sentido coletivo - não é uma estrutura rígida de laços sociais, mas passa a existir através dos vínculos provisórios das associações entre humanos e não-humanos, que se configuram em seus espaços" (Azambuja, 2012, p.15). A performatividade imanente nesta ferramenta metodológica sugere alguns requisitos básicos a serem observados, no entanto, destacamos aqui o que nos parece essencial para este trabalho: a produção de conhecimento se dá em rede e não com base em ideias preestabelecidas. 
A rede não é contexto ou intermediação, é uma referência utilizada para descrever o mundo [...] Não é produto, mas processo. Não é um dado, mas resultado. O social, nestes termos, pode ser analisado com base nas suas interações ativas, podendo ser performado. E o ator (ou actante) é tudo o que age nessa rede, e que deixa efeito neste mundo. Nunca está sozinho, pois sua atuação é distribuída [...] A rede é, portanto, uma 'ferramenta metodológica' a partir da qual não apenas acompanhamos ou descrevemos as coisas do mundo, mas, acima de tudo, criamos um mundo. Na observação de determinadas situações, o que interessa é seguir os atores em ação, suas conexões e os efeitos que eles apresentam (Azambuja, 2012, p.33).

Se para a TAR - referencial metodológico aqui definido -, o fluxo possível entre online e offline pode ser rastreado a partir de suas múltiplas conexões ativas em seus muitos movimentos, cabe-nos, para efeito deste artigo, uma estabilização temporária no sentido de compreender (mesmo que parcialmente) algumas ocorrências no contexto das mídias convergentes. Levantamos, portanto, como possibilidade metodológica, a rede sociotécnica - que não faz distinção entre humanos/ não-humanos, social/ natural, online e offline - e está aberta às controvérsias capazes de abrir caixas-pretas 4. O "fio de Ariadne destas histórias confusas" (Latour, 1994, p.9), por fim, possibilitará, de alguma forma, a visualização mais detida de alguns fenômenos que emergem das ações digitais/ não digitais contemporâneas.

\section{Mapeamento a partir do Caso Marie: como levantar instabilidades e controvérsias?}

Redes sociais na internet, entendidas aqui também como instrumentos de mediação, podem configurar novos espaços de discussão e aprendizagem, proporcionando difusão de conhecimento, ideias e opiniões, além de outras conexões situadas para além dos contratos estabelecidos pelos meios tradicionais de comunicação. Curiosamente, alguns eventos fluem entre as zonas de convergência online e offline, sendo transportados das páginas pessoais (de interesse individual) para situações de repercussão coletiva (através da mídia massiva). Seguindo no sentido de performá-las e compreender alguns dos desdobramentos e implicações possíveis, o trabalho aqui apresentado - que tem início com o monitoramento de uma rede de conexões rastreadas a partir do Caso Marie - busca identificar principais controvérsias ao observar conversas entre 
indivíduos, compartilhamentos, ações virtuais coletivas, articulações no espaço físico, cobertura da imprensa etc.

De início, uma análise preliminar nos aponta que estes eventos têm relação direta ou com a construção de capital social de alguns indivíduos ou com determinadas redes de ciberativismo, a partir dos quais observamos uma primeira controvérsia interessante - o que para André Lemos (2013) "é o momento onde ficam mais visíveis os actantes ${ }^{5 "}$ (p.106). Observamos, portanto, informações fluírem de espaços íntimos, livre de regras formais, para centros deliberativos de ações mais efetivas, como uma espécie de apropriação feita a partir do capital social anteriormente instituído. Para Raquel Recuero(2009), o capital social é o valor que se constitui a partir das interações e práticas de conversação entre os atores sociais (p.45), o que, de alguma forma, não se restringe às conexões iniciais mapeadas no caso em questão, mas reverbera em práticas sociais múltiplas, seja no nível comportamental, cultural ou dentro da própria esfera política, muitas vezes, envolvendo também redes de ciberativismo.

Bruno Latour (2005) nos convoca a seguirmos controvérsias, assim, a escolha por esse objeto complexo esteve pautada a todo tempo na necessidade de compreendermos diferentes conexões possíveis de uma rede em movimento constante. Em específico, no Caso Marie, instabilidade aparece como uma palavra de ordem, principalmente, quando um fato absolutamente particular (a exposição de fotos íntimas de uma pessoa na internet) se revela eficaz de mobilizar um grande contingente de pessoas que, a partir dessas questões, se manifesta contra comentários e ações, para elas, negativas e não consensuais. Além disso, outras vítimas desse tipo de ação também se posicionam em favor de Marie, demonstrando a amplitude do fato. A partir desse caso, o assunto ganha visibilidade, exigindo de todos os envolvidos um olhar mais crítico em relação ao tema, e ações públicas mais efetivas contra esse tipo de atividade na internet. E assim, passamos a ter mais "atenção às controvérsias da ação em curso" (Azambuja, 2012, p.38).

De início, os vídeos pessoais da adolescente migraram de mensagens no whatsapp para as redes sociais e a sua vida privada foi invadida de forma rápida e avassaladora. Em matéria veiculada no portal G1, observamos (através de depoimento) os efeitos iniciais do fato na vida de Marie: "mãe de uma menina de 2 anos, teve que mudar a aparência e parar de trabalhar. Hoje, ela evita sair de casa" ${ }^{6}$. 


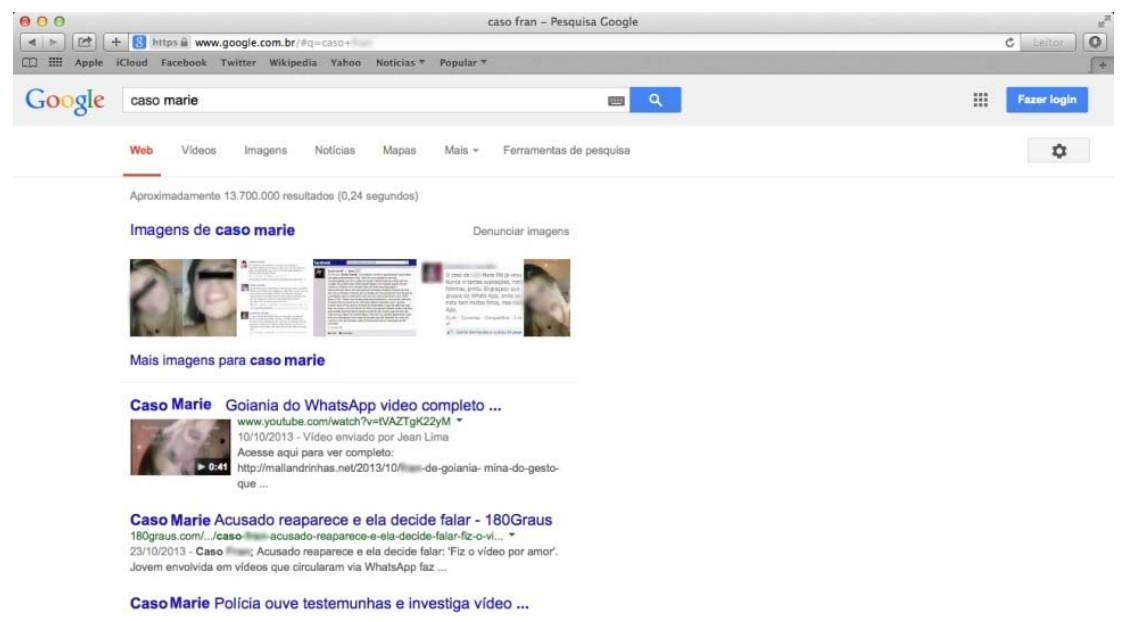

FIGURA 1 - Em pesquisa rápida com ferramenta de busca, localizamos, aproximadamente, "13.700.000 resultados, em 0,24segundos". Os 200 primeiros links, das formas mais variadas, estavam vinculados ao caso em questão, sendo que as fotos íntimas ilustravam o topo da página. ${ }^{7}$

Em pouco tempo, já havia comentários, compartilhamentos, memes 8, críticas, grupos de discussão, matérias na imprensa nacional e local. Blogs de diversos tipos, de grande alcance, comentavam o fato, e o número de apoiadores (ou não) à Marie aumentava. Setores feministas, familiares e amigos se uniram contra o cyberbulling ${ }^{9}$, e a favor da jovem. Os embates, como observaremos na análise a seguir, giravam em torno do julgamento em relação à atitude da jovem de se expor através de fotografias, de ideias a respeito da liberdade do corpo feminino, a moral, o machismo etc. A violência e o apoio surgiram de diversas partes e de diversas formas (links para o vídeo que já estava no youtube, fotos, muitos comentários, informações em blogs, em jornais etc.), sendo multiplicados nas redes sociais de modo quase instantâneo. Rapidamente foi criada uma página no Facebook, chamada Apoio Marie (FIGURA 2), produzida por amigas e que possuia uma linha claramente feminista. Na página eram divulgadas matérias sobre o assunto, depoimentos de pessoas que passaram pela mesma situação ou da própria Marie, que, na época, havia cancelado sua conta no Facebook. Enquanto isso, outras páginas (FIGURA 3) também eram criadas com o objetivo de ricularizar o caso e a própria Marie, considerando o destaque dados às suas imagens. 


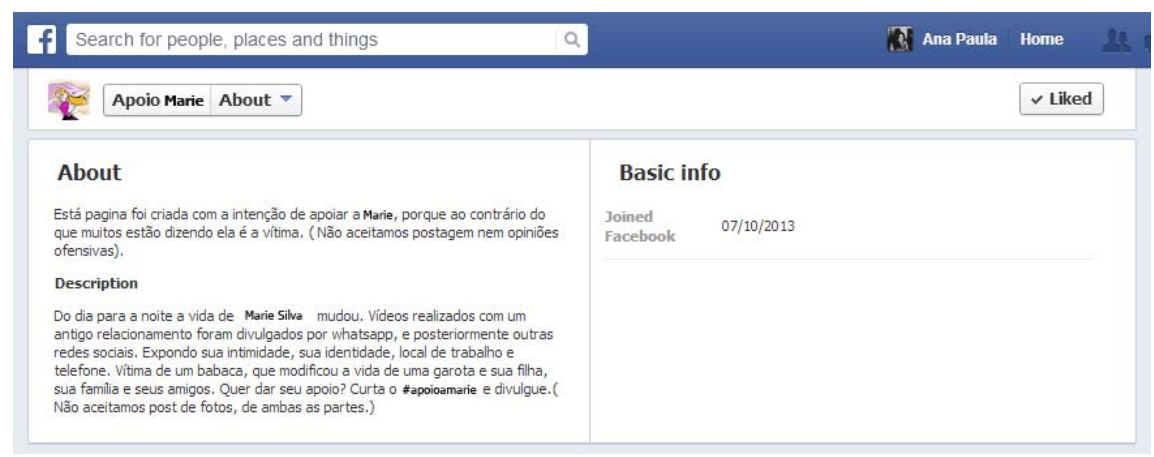

FIGURA 2 - Página no Facebook criada em 7 de outubro de 2013.

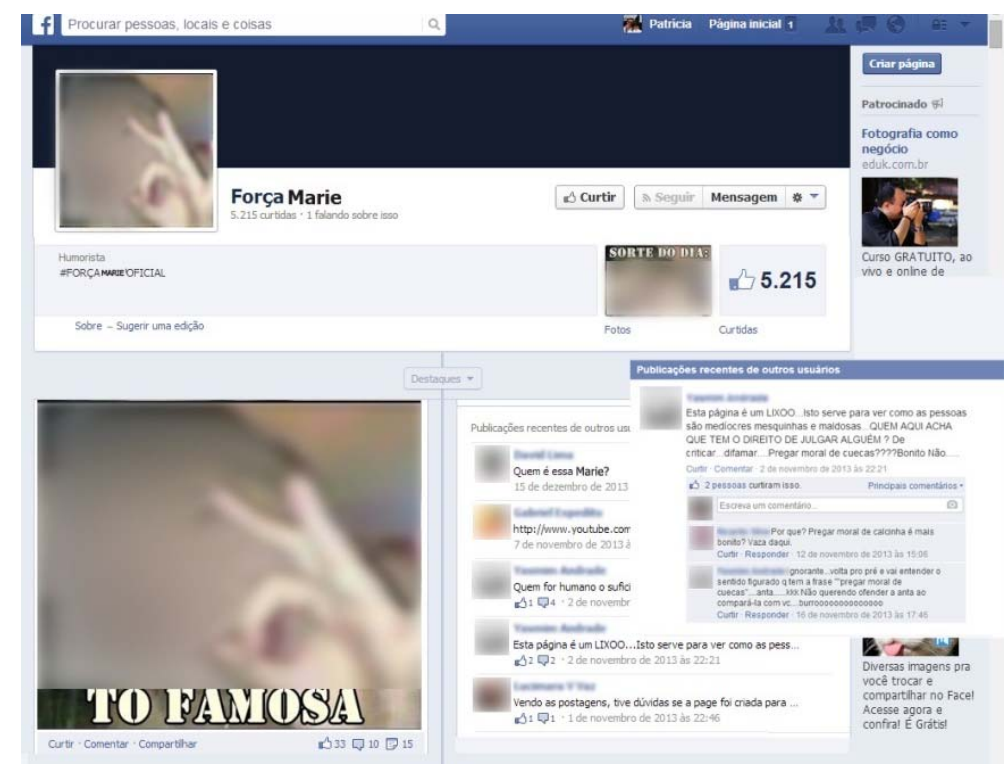

FIGURA 3 - Página no Facebook, criada em 8 de outubro de 2013, colabora com a divulgação das primeiras imagens.

\section{Teoria Ator-rede e análise de redes sociais: "conversações" possíveis}

Algumas das ferramentas computacionais aqui analisadas começam a organizar "espaços de conversação" importantes. Para Raquel Recuero (2012), não são possuem apenas um viés tecnológico, mas passam a evidenciar situações e interesses referentes ao contexto de interação, que se configura a partir da conversação. Por isso, o seu livro A Conversação em Rede foca principalmente "nas conversações que emergem e estabelecem os rastros dos usuários nesses espaços. As características dos sites de rede social, nesse contexto, acabam gerando uma nova 'forma' conversacional, mais pública, mais coletiva" (p.17).

Muitas dessas redes discutem mudanças sociais capazes de suprir anseios individuais e, também, de setores sociais mais amplos. A 
partir do sentimento de uma necessidade, de um direito não garantido, de uma inquietação, debates e discussões são iniciadas, muitas vezes, com divergências entre os próprios atores, e com poder latente de gerar ações mais concretas. A Marcha das Vadias ${ }^{10}$, por exemplo, começou dessa forma em São Luís, a partir de uma inquietação entre mulheres ludovicenses relacionada aos estupros na capital e à forma como a sociedade local via e tratava a mulher. Inquietação essa apoiada por marchas e lutas em diversas localidades, pelo mesmo motivo, e com discussões no mundo inteiro sobre o direito ao próprio corpo. A partir disso a questão foi pauta em rede de amigas, espalhou-se e aconteceu efetivamente em espaço público da cidade.

Importante destacar que o evento foi organizado com o auxílio da web, estabelecendo, assim, um novo espaço de mobiilização para as mulheres em São Luís.

Raquel Recuero (2009) afirma que no decorrer da conversação estabelecida entre os atores é essencial compreender as ações da rede, do grupo, e dimensionar a sua força no ambiente offline, com a mídia, a opinião pública, e, principalmente, o poder público, através do capital social acumulado e de suas implicações. O valor do capital social pode ser observado muitas vezes a partir das interações e práticas de conversação, e as FIGURAS 4 e 5 exemplificam a forte relação possível entre as ferramentas online de organização e seus efeitos para a mobilização em espaço público, gerando pauta inclusive para o jornalismo local (tanto escrito como televisionado).

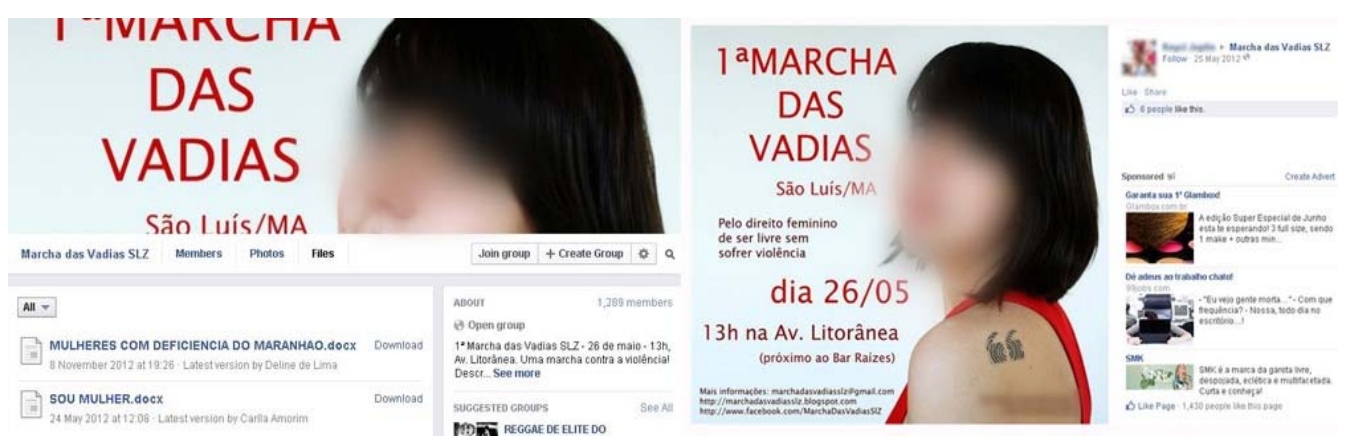

FIGURA 4 - Páginas do grupo de organização local da Marcha: espaço de construção e debate dos ativistas participantes e apoiadores do movimento. 


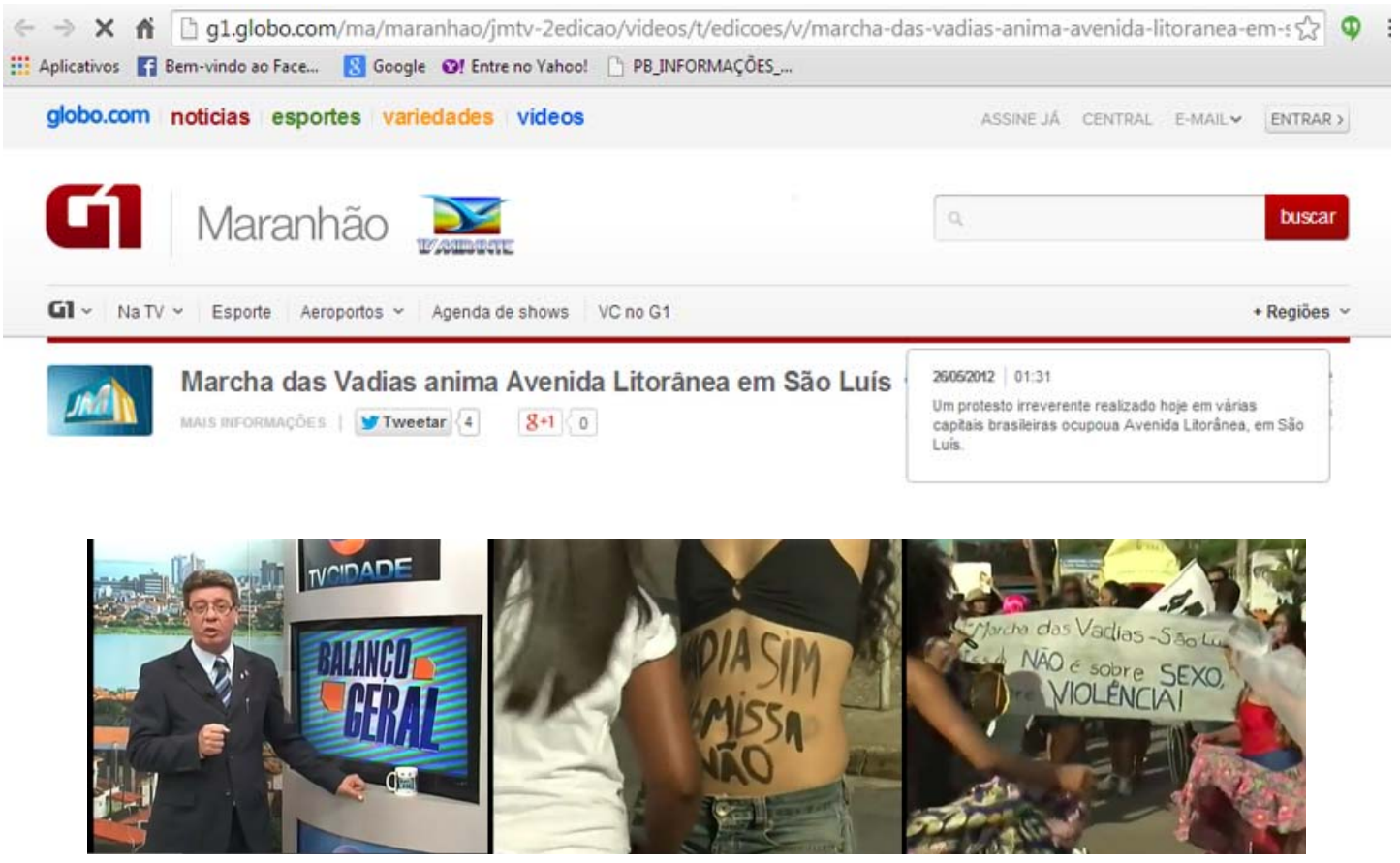

FIGURA 5 - Marcha das Vadias em São Luís noticiada em portal Gl Maranhão (portal de notícias) e por telejornal local (frames retirados do vídeo).

Portanto, em relação ao Caso Marie, nos lançamos em busca de questionamentos vinculados ao capital social dentro dessas redes, e ações que se desprendem desses espaços de tensão. Por vezes, "simples" comentários, em outras, práticas criativas nas estratégias de conversação. De fato, é possível perceber essa dinâmica de mobilização a partir da análise dos traços e dos diversos acontecimentos em torno do caso. É desse percurso de ações online que são retiradas as primeiras pistas para observação da rede de associações, para assim, analisarmos rastros e vínculos para além dos núcleos de conversações. Identificando, também, possíveis desdobramentos concretos e/ou materiais. Segundo Bruno Latour (2005), para Teoria Ator-rede (TAR) não há separação entre sujeitos e objetos, humanos e não-humanos, natural e social, ou mesmo, real e virtual. A produção de conhecimento se dá em rede e não com base em conceitos preexistentes. Assim, a TAR é oferecida por Latour (2005) como uma ferramenta metodológica a partir da qual não apenas descrevemos o potencial de conexões do mundo, mas inevitavelmente criamos um mundo.

Para os teóricos da TAR - de base etnometodológica amparada em trabalho empírico - o curso da ação social deve seguir as tramas de conexões oferecidas pelo encontro entre o pesquisador e o contexto sociotécnico observado (e não acabado). André Lemos (2013b) e Fernanda Bruno (2012) identificam este método como Cartografia das Controvérsias (CC), e Lemos (2013b) traça uma analogia entre os trabalhos do cientista social e do jornalista. 
A pureza dos fatos é a pedra de toque destas aspirações, tanto no campo científico, quanto no jornalístico [...] Eis a primeira contribuição trazida pela TAR: a purificação dos fatos não é a melhor abordagem nem para o trabalho, nem para a pesquisa, nem para a comunicação (Lemos, 2013b, p.71).

No sentido de praticar a ideia da sociologia em ação, introduziu o método de cartografar controvérsias a uma turma de graduação, e comparou este trabalho ao do jornalismo investigativo, no qual o repórter deveria seguir o fato, observar as marcas deixadas, analisálas e compor o texto a partir dos seus aspectos.

Para Lemos (2013b), o momento principal para qualquer análise é a controvérsia, a polêmica (p.33), quando as estabilizações produzidas pelas caixas-pretas são ameaçadas pelo movimento de outras conexões possíveis (nem sempre aparentes à primeira vista). São essas instabilidades e ações que precisam ser identificados e analisados em seus desdobramentos. "O trabalho do analista é se deslocar por estas fronteiras, seguir os actantes, mapear os rastros em uma busca contínua das associações criadas pelos e entre os atores que observa" (p.73).

Nesse sentido, os movimentos produzidos a partir das interações online, por exemplo, apontam a diversidade de reverberações possíveis tanto nos espaços virtuais como nos reais. O que demonstram a necessidade preeminente de pensar o social sob sua configuração complexa, dinâmica e, definitivamente, instável. Observar controvérsias, abrir caixa-pretas, desfazer o lugar-comum, o óbvio, ou simplesmente seguir redes de associações, nos permitirão discutir em torno de outros olhares existentes. Enfim, "construir" novos mundos.

\section{Mapa de instabilidades e reverberações preliminares no Caso Marie}

Nas análises preliminares sobre os desdobramentos do Caso Marie, algumas movimentações na rede foram significativas ao longo do processo de observação - de outubro de 2013 a abril de 2014.

1) A primeira ação é a própria controvérsia: enquanto uma pessoa tem sua intimidade exposta a partir de aplicativo de conversa de celular (whatsapp), o que se observa a partir de algumas ações subsequentes - considerando que assunto se espalha de forma muito rápida - são tensões favoráveis e desfavoráveis que apenas alimentam ainda mais a rede de violência e preconceito (FIGURAS 1, $2,3$ e 6$)$. 
Um recadinho especial para os moçolos que apolaram o namorado babaca que divulgou o video com a ex namorada (e estăo compartihando ele a torto e a dreito pelo watsap): $A$ măe de vocêss também transa.

Curtir " Comentar " Comparthar * ha 22 horas *

- outras 66 pessoas curtiram ino.

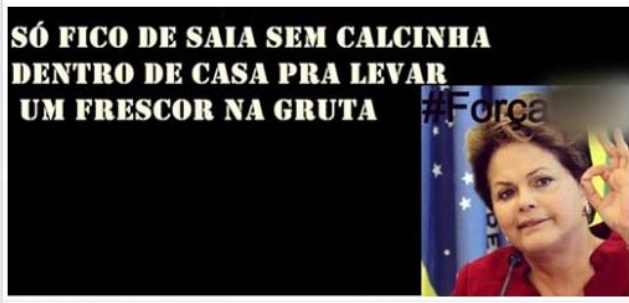

FIGURA 6 - Posts retirados de diferentes páginas.

2) A complexidade da rede se apresenta através das muitas vozes divergentes nas páginas criadas, nas fotografias, memes ou links compartilhados. E uma página de apoio é produzida por amigas, promovendo uma ação mais "solidária" em torno do Caso Marie.

gente e a marie como ela esta?ja voltou sua vida normal?de

noticias

Curtir - Comentar - 21 de janeiro às 18:56

称3 pessoas curtiram isso.

Escreva um comentário

Apoio MARIE Estou bem, voltei sim vida normal e mais forte

doque nunca ! (:) beijo e obrigada pela preocupação ! :*

Curtir - Responder - 6 - 22 de janeiro às 10:14

FIGURA 7 - Comentários de apoio na página do Facebook.

3) A partir deste caso em específico, que começa a atrair a atenção dos meios de comunicação, outros casos semelhantes são apresentados à sociedade, com desenlaces danosos para os envolvidos. Vínculos concretos entre ações online e repercussões offline. 


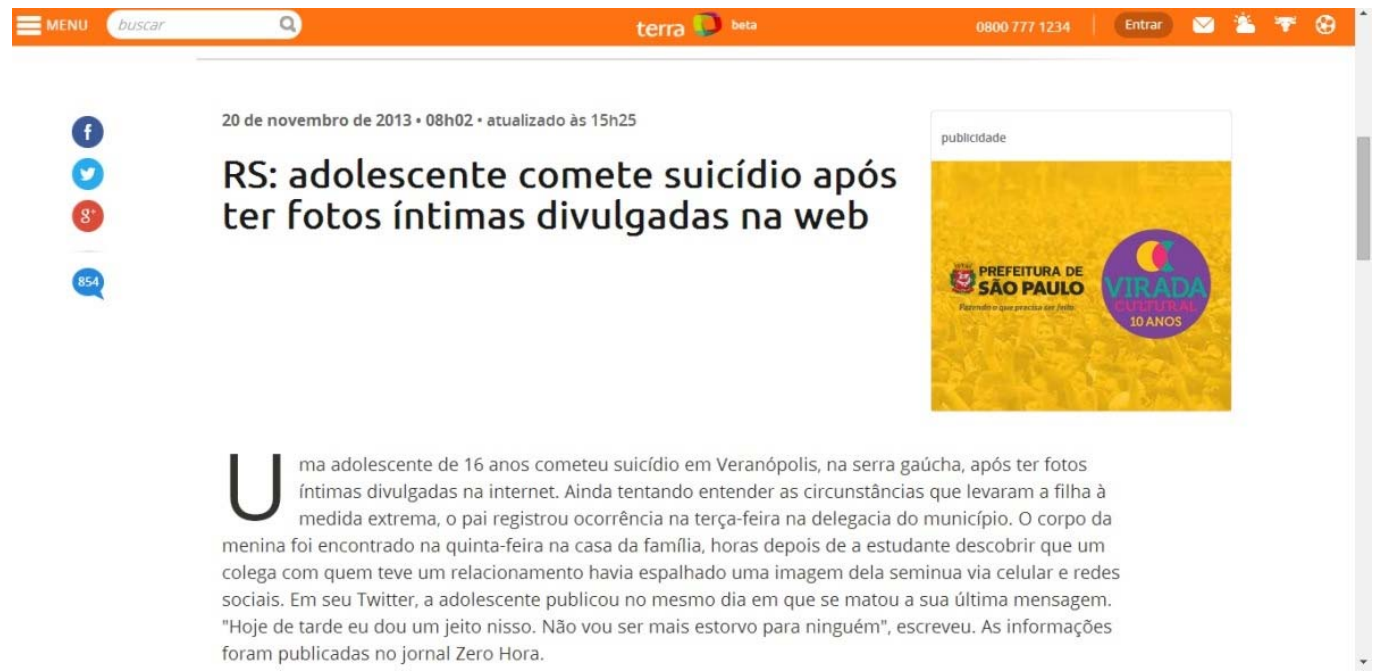

FIGURA 8 - Notícia publicada no Portal Terra (e em outros sites de informação), no dia 20 de novembro de 2013.

4) Paralelamente, movimentações acontecem a partir das repercussões e debates em torno do fato íntimo inicial. Não havia mais apenas um tema polemizado por um grupo de "amigos", seu significado e suas consequências estavam sendo debatidos, atingindo um coletivo de pessoas. Em outras palavras, os acontecimentos ganhavam uma dimensão de problema a ser resolvido socialmente e politicamente, somando iniciativas do âmbito das esferas privada e pública.

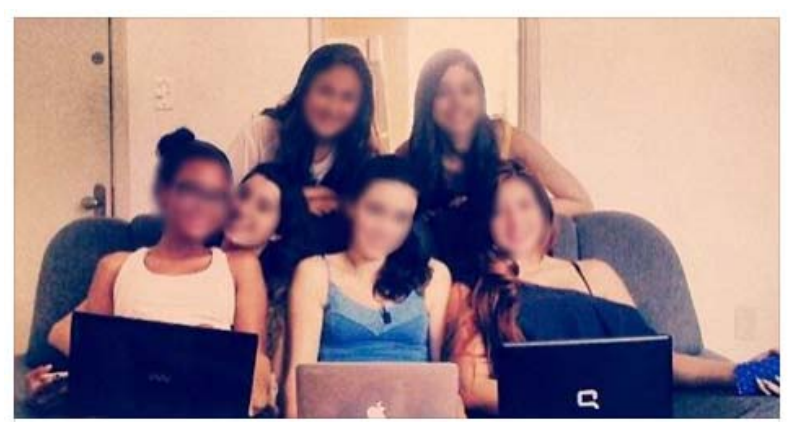

Meninas criam aplicativo para combater o slut shaming

Um grupo de seis meninas de 16 anos de idade criaram um aplicativo de celular para enfrentar o que consideram o maior problema de sua comunidade: 0 slut shaming depois do vazamento de fotos intimas. A ideia é... BRASLPOST COM.BR I GYGABRELA LOUREIRO 


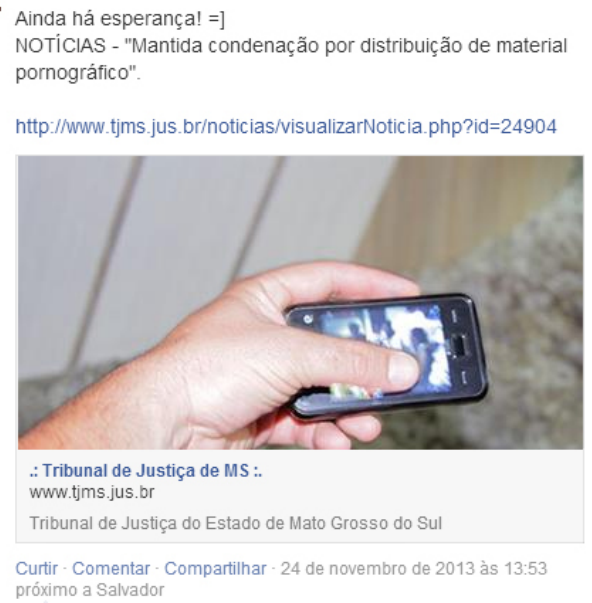

\section{Brasil: Após suicídios, Romário se vira contra vazamento ilegal de relações íntimas na web}

Conduta criminosa tem vitimado um número cada vez maior de pessoas; relembre alguns casos

20 de novembro de 2013 - 4:06 PM Autor: Daniel Alencar Categoria: Brasil, Destaque 0 Comentários

FIGURA 9 - Três exemplos de iniciativas locais e globais com o objetivo de anular ações similares ao de Marie.

5) Mobilizações e ações dentro e fora da rede ganham apoio dos legisladores, e as vítimas começam a vislumbrar amparos nas leis, com a possibilidade de penas mais severas aos agressores e aos sites que postam esse tipo de conteúdo.

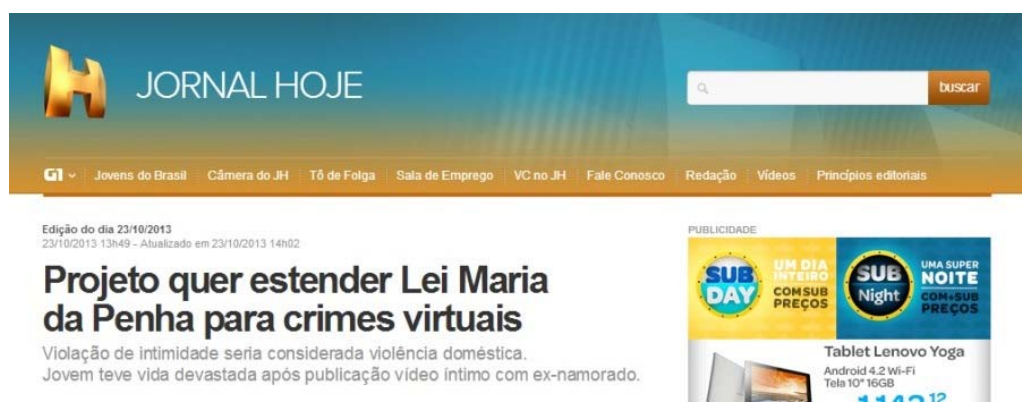

FIGURA 10 - Matéria veiculada no Jornal Hoje, do dia 23 de outubro de 2013, com o depoimento de Marie e a informação sobre um projeto do Deputado J oão Arruda, do Paraná, que "prevê que qualquer divulgação de imagens, informações, dados pessoais, vídeos ou áudios obtidos no âmbito de relações domésticas, sem o expresso consentimento da mulher, passe a ser entendido como violação da intimidade. Essa violação de intimidade, pela proposta, passaria a ser considerada violência doméstica. Segundo o procurador da Justiça de São Paulo, Paulo Marco Ferreira Lima, a mudança é bem vinda, mas no caso da internet a punição deveria ser maior. 'Considerando que a internet aumenta e muito a divulgação disso, deveria ter uma pena qualificada, ter uma causa de aumento de pena pelas consequências dessa prática', defende". 


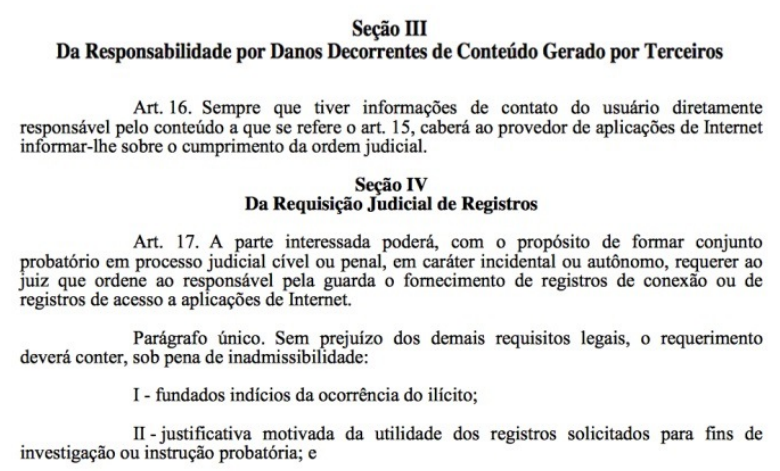

FIGURA 11- Acima, trecho do Marco Civil, aprovado em abril de 2014, que sugere ao autor da primeira postagem com o conteúdo sem autorização punição com base na legislação penal existente.

\section{Online/ Offline: formas híbridas de organização do espaço público}

O que percebemos, a partir da observação mais detida desses movimentos da rede, é que o que configura essas manifestações não se constitui pela diferenciação incondicional entre online e offline, mas sim por suas múltiplas possibilidades de intersecção e coexistência, assim como, pela conexão entre os indivíduos, os lugares que habitam, as coisas que adquirem, os valores que possuem, suas associações e ações. O espaço do "ciberespaço", para André Lemos (2013a), está sempre em construção, é dinâmico, móvel e associativo. "A internet vai produzindo espacialização na relação dos lugares e nas movimentações pelas conexões de tudo e todos, em um espaço de controle que se faz e se desfaz nesse movimento, no tempo" (p. 57).

Assim, além do seu potencial ligado aos jogos de lazer, a comunicaçcão interpessoal ou a simples divulgação de conteúdos de informação e entretenimento ligados às corporações midiáticas, a internet $e$ as redes sociais digitais podem ser observadas como espaços para além do conversacional, também, mediadoras do discurso social, do debate ideológico, da mobilização coletiva, em alguns casos, uma oportuna "arma" contra-hegemônica.

Por esta ótica, algumas redes digitais que se formam dão vazão a anseios sociais de minorias, de segmentos sociais de todo o tipo e toda sorte. De modo que, parece-nos evidente que há sim grande diversidade de temas, assuntos, informações, contextos, configurações espaciais/ materiais e comportamentos, sempre em constante movimento. O que, por outro lado, também não aparece dissociada das antigas formas de organização, nas redes sociais offline do "passado". Manuel Castells (2003) utiliza como exemplo o movimento operário na Era Industrial, que tinha a fábrica como 
infraestrutura material de mobilização (ou como alguns historiadores afirmam, também, os pubs). Assim, o que temos na Era da Informação são outras configurações e ajustes, considerando novas práticas de organização a partir da web. A "internet não é simplesmente uma tecnologia: é um meio de comunicação (como eram os pubs), e é a infraestrutura material de uma determinada forma organizacional: a rede (como era a fábrica)" (p.116). Castells (2003) pontua três razões que destacam as redes digitais como componentes indispensáveis para pensar as formas de organização que emergem na sociedade atual:

os movimentos sociais na Era da Informação são essencialmente mobilizados em torno de valores culturais; [...] têm de preencher o vazio deixado pela crise das organizações verticalmente integradas, herdadas da Era Industrial; [e considerando que]; o poder funciona cada vez mais em redes globais, passando em grande parte ao largo das instituições nacionais, os movimentos se defrontam com a necessidade de obter o mesmo alcance global dos poderes vigentes, exercendo - seu próprio impacto sobre a mídia, através de ações simbólicas (Castells, 2003, p.116-118).

Portanto, pensar a mobilização social no contexto das tecnologias em rede passa inevitavelmente pela percepção detalhada também de valores culturais, anseios e necessidades expressas pelos cidadãos e suas possíveis conexões locais e globais, considerando as relações para além do discurso e da linguagem, percebendo também aspectos materiais do espaço onde essas relações são instituídas.

Neste trabalho, quando utilizamos o Caso Marie - um caso de grande repercussão na internet - como recorte inicial para as investigações, visamos performar um pequeno mapa de tensões, debates e influências, a partir do qual, tornou-se possível visualizar a fluidez entre os ambientes online e offline, variações em torno das opiniões dos públicos, os diferentes comportamentos individuais, consequências danosas, ações criativas etc. Assim, observamos um tema eclodir da relação entre duas pessoas à condição de pauta relevante para a sociedade.

Durante os meses de outubro, novembro e dezembro de 2013, o tema da pornografia de vingança ${ }^{11}$ ganhou espaço em diversos sites, e pareceu entre os termos, tanto em inglês quanto em português, que saíram de uma zona de desconhecimento para uma zona de intenso debate e discussão, envolvendo inclusive mulheres vítimas desse tipo de ação. O Caso Marie não foi o único na época, casos de suicídio de adolescentes, também com vídeos íntimos viralizados na internet, tornaram a questão ainda mais grave. 
No início o termo mais utilizado era porn revenge, retirado do inglês e que ganhou versões em português como pornografia de revanche e pornografia de vingança. Neste caso, o significado não muda, todos os termos representam o ato de exposição de material íntimo de alguém com intuito de denegrir sua imagem.

Através do site Google Trends, podemos visualizar o período de maior interesse pelo assunto, através de buscas na web utilizando o termo.

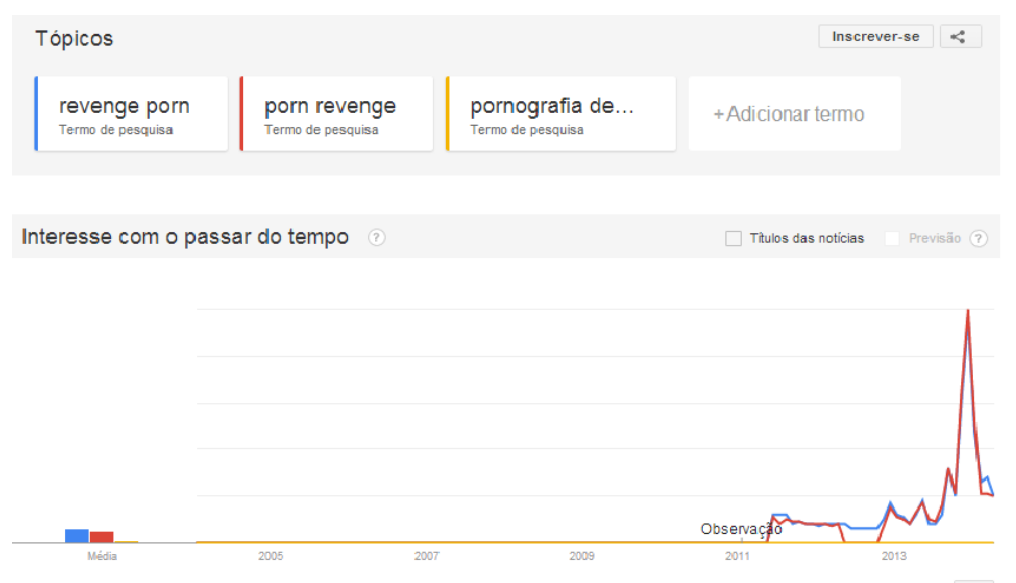

FIGURA 12 - Via Google Trends, constata-se o período em que o termo repercutiu na internet.

É perceptível que nos períodos de outubro a dezembro de 2013, o termo tenha sido mais utilizado em decorrência, sobretudo, da atenção que os casos receberam com as notícias de suicídio de adolescentes superexpostas. O assunto acabou saindo na internet e ganhou espaço nos meios tradicionais de comunicação, gerando discussões mais acaloradas e exigindo ações mais severas aos agressores. A própria legislação vigente ainda não está preparada para esse tipo de ação criminosa no ciberespaço, tratando-os, quando muito, como crimes de injúria ou difamação.

Não só a legislação, mas o debate feminista ocupou a pauta e os espaços de discussão, de luta e, assim, as próprias vítimas conseguiram algum conforto. Na página Apoio Marie (FIGURA 2), criada por amigas da vítima e com forte influência feminista, encontramos um desses lugares de amparo, com matérias a respeito e um intenso debate em torno de assuntos relacionados. A ideia central defendida é a de que a culpa do vazamento do conteúdo não poderia ser, única e exclusivamente, da vítima, mas também de quem posta ou de quem compartilha. As meninas, muitas vezes, são imediatamente julgadas porque se deixam filmar, fotografar ou, simplesmente, pelo fato de serem mulheres. Portanto, o que parece ter vitimado Marie e as outras, mais do que conteúdo íntimo publicado, talvez tenha sido o julgamento social, o abuso do uso da imagem e a própria perseguição que sofreram ao serem reconhecidas 
em espaços públicos fora da internet. Em rápida pesquisa pelo Google observa-se, ainda hoje (quase um ano após o fato), o tamanho da exposição sofrida por Marie (FIGURA 1).

Outro exemplo, a hashtag \#forçamarie, utilizada por seus apoiadores, virou piada na web sob forma de viral: utilizando a hashtag e o sinal de 'ok' com as mãos, semelhante ao que foi feito pela Marie no vídeo. O que aumentou ainda mais a onda de indignação e apoio em torno do caso, ganhando mais atenção e alcance do público.

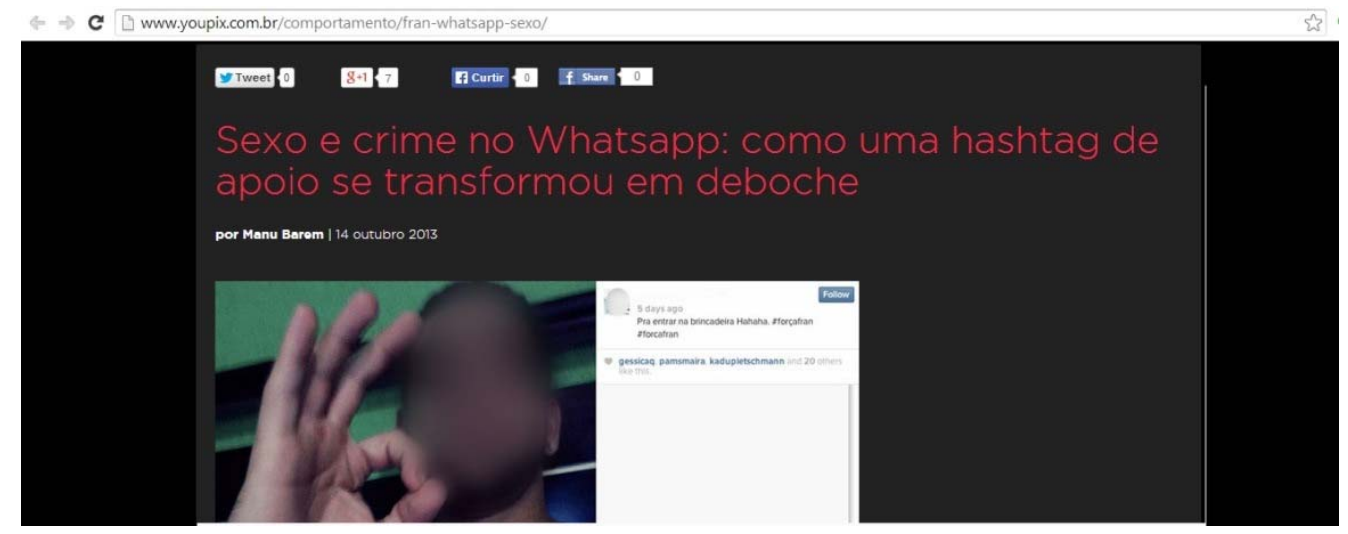

FIGURA 13 - Matéria no site de tecnologia e comportamento, Youpix, sobre a viralização das ações de bullying contra a Marie na web.

\section{Uma rede que não se esgota...}

O que parece ocorrer nos casos de pornografia de revanche é que as vítimas são brutalmente expostas não apenas em decorrência do conjunto de imagens e/ou informações compartilhadas inicialmente. A capacidade e a velocidade dos compartilhamentos através das plataformas fixas ou dispositivos móveis, cada vez mais acessíveis, favorecem a multiplicação rápida dos conteúdos colocados na rede, e a espantosa impossibilidade de contê-la. Muitas vezes, mesmo sem intenção, um despretensioso "curtir" colabora com ações maliciosas. As vítimas, então, são expostas a partir das imagens, dos comentários maldosos ou das opiniões mais contundentes de quem nem mesmo as conhecem. Os fatos atingem um grande contingente de pessoas, que se sentem na obrigação de terem algum tipo de opinião sobre o comportamento das vítimas e, nesse instante, o cyberbulling ganha a dimensão de julgamento popular. Marie, em entrevista ao Fantástico, relatou que teve que mudar a própria aparência e parar de trabalhar quando entendeu o que realmente tinha acontecido: “Meu celular não parava. O pessoal ligando, ligando. Eu fiz o boletim de ocorrência na sexta-feira. O pessoal não 
tinha dado muita importância. Quando foi na segunda-feira, eu vi a proporção que tava" ${ }^{12}$.

O julgamento sofrido é um instante tão traumático quanto o de ter sua intimidade violada por alguém de sua confiança, chegando ao ponto de algumas adolescentes se suicidarem por não suportarem a vergonha e a humilhação (tanto na rede quanto nos espaços sociais de convívio). Outras mudam suas vidas completamente para fugirem da perseguição e, enquanto isso, as informações continuam sendo multiplicadas. E o agressor, aquele que primeiro liberou o conteúdo em rede, não é punido de forma proporcional ao dano causado.

Abalada e com o visual diferente, para não ser reconhecida nas ruas, ela conta que está há praticamente 20 dias sem sair de casa. A estudante, que era vendedora em uma loja de roupas, resolveu falar publicamente sobre o caso, que ela considerou "humilhante", porque, segundo ela, está sendo condenada por muitas pessoas que não conhecem toda a história. ‘Eu não cometi nenhum crime. Mas pessoas me ofendem virtualmente e moralmente. Muita gente me chamou de vadia, prostituta. Um homem chegou a me mandar uma mensagem falando que viria a Goiânia no final de semana e que me pagava $\mathrm{R} \$ 10$ mil para sair com ele', afirma. ${ }^{13}$

O que foi possível perceber a partir da estabilização temporária dessa rede de conexões é que o tema não se esgota na observação do Caso Marie. Ou melhor, os fenômenos sociais nos são apresentados sob forma de conexões rastreáveis, um coletivo de associações entre elementos híbridos (humanos e não-humanos) (Latour, 2005), e em movimento contínuo. Uma ação individual na web não é isolada, ou completamente local, sempre ganha adeptos que, primeiramente, concordam ou discordam dela. E assim, através de compartilhamentos e comentários, vai sendo ampliada, podendo atingir proporções de grande evento.

Casos como de Marie - apresentado aqui em suas múltiplas conexões - levantam questões importantes sobre o modo como compartilhamos informações hoje. Nem sempre ponderação é um actante presente na rede, ou reflexão sobre efeitos e consequências. A impulsividade, a necessidade de pertencimento a determinado grupo (influenciando diretamente em valores de capital social), ou simplemente a vontade de ser ouvido a qualquer custo, parecem ditar as regras do jogo. E acabamos não percebendo que, ao curtir, comentar, buscar reconhecimento pessoal ou recompensas, alimentamos uma rede bem maior que aquela imediatamente à vista. No mínimo, somos coautores das ações resultantes. 


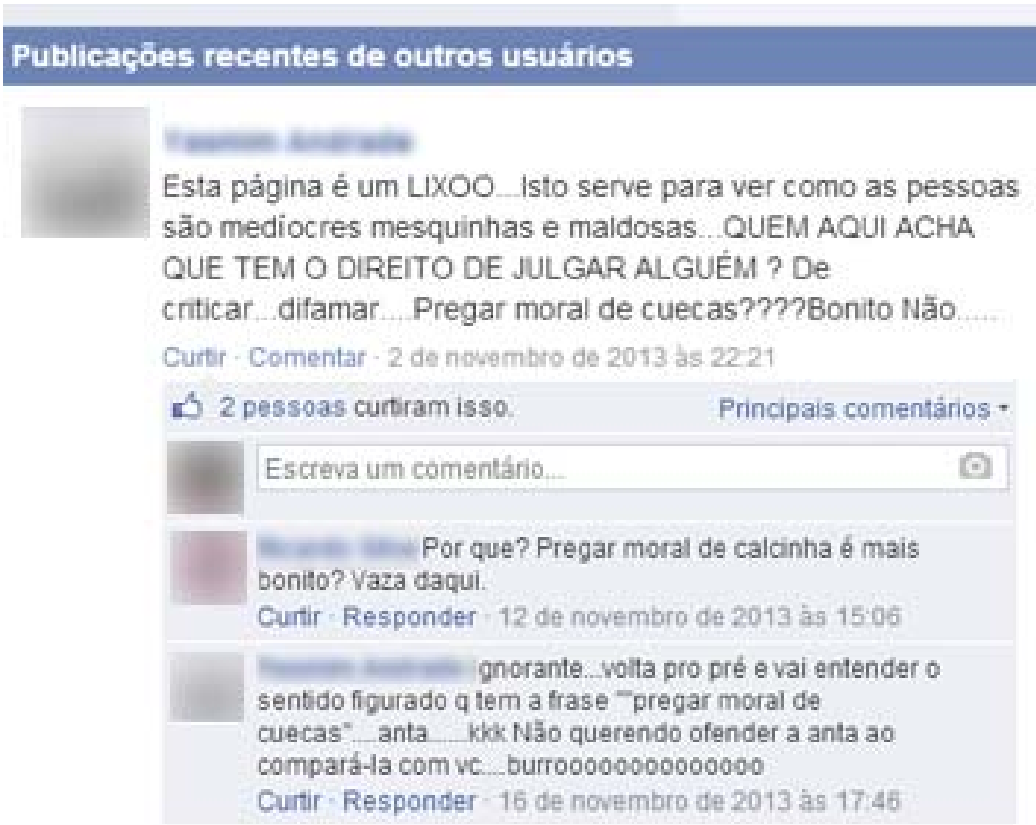

FIGURA 14 - Detalhe de algumas “opiniões" na página criada para divulgar as primeiras imagens no Facebook

Steven Johnson (2003) afirma que, se estamos buscando aprender com sistemas a partir dos quais a adaptabilidade advém de conhecimento local, há alguns princípios que precisam ser seguidos, entre eles: "a informação local pode levar à sabedoria global" (p.58). $\mathrm{O}$ autor busca desvincular a ideia de enxame ${ }^{14}$ ao de multidão (século XVII) ou massa (século XIX) de cabeças não pensantes, influenciáveis e sem algum princípio organizador.

O que nos parece importante, a partir dos rastreamentos promovidos no Caso Marie, é observar que, mesmo de forma complexa e ganhando dimensões notadamente imprevisíveis, nos deparamos aqui com a necessidade de uma compreensão mais detida dessas ações, até porque - como vimos nessa estabilização temporária de rede - elas têm força.

Cabe a todo o coletivo social esse entendimento - a nós pesquisadores, aos jornalistas que investigam os fatos, aos ciberativistas e, sobretudo, a cada indivíduo que se sente tentado a compartilhar informações através dos mecanismos que estão sempre à mão: o de visualizar conexões e desdobramentos possíveis. Assim, buscamos levantar aqui reflexões acerca de algumas práticas com as tecnologias (digitais ou analógicas), no sentido de compreendermos que, inevitalvemente, a rede de vínculos possíveis está sempre aberta, e envolvida com questões relacionadas à liberdade de expressão, ações criativas, de mudança, censura, preconceito etc. É múltipla, heterogênea e, nem sempre, previsível.

A página de Facebook Apoio Marie não foi desativada, mas deixou de ser alimentada pelos administradores em dezembro de 2013. Mesmo 
assim, vídeos e fotografias pessoais suas, mensagens postadas (ofensivas ou não), piadas, memes irônicos, notícias veiculadas, ações concretas de transformação etc. ainda circulam livremente pela rede - acessíveis a qualquer indivíduo que tenha um computador (portátil ou não) e uma conexão simples de internet.

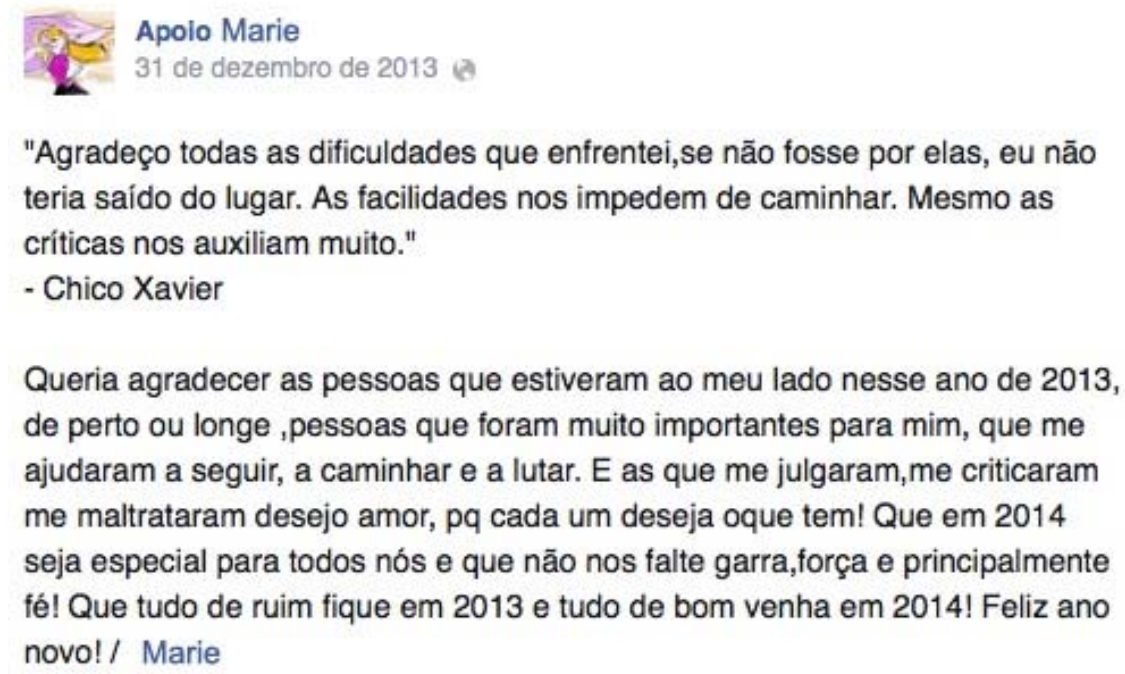

Curtir - Comentar - Compartilhar

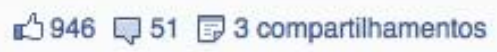

FIGURA 15 - Último post da página Apoio Marie, em 31 de dezembro de 2013.

Por fim: se por um lado, necessitamos cada vez mais cautera em relação ao conteúdo que divulgamos sobre nossas vidas - porque dele depende o nosso capital social -; o mesmo vale para o grau de atenção que dedicamos às muitas informações espalhadas na rede porque através dele construímos o capital social do outro.

\section{Referências}

Azambuja, P. (2012). Cognição e Mediação Técnica: passagem analógico-digital da recepção de TV sob a ótica da Teoria atorrede. Tese de doutorado, Universidade do estado do Rio de Janeiro, Rio de Janeiro, RJ, Brasil.

Azambuja, P., \& Monteiro, M.(2012). Recepção transmidiática: incursões pela Teoria Ator-rede. Revista Comunicación, I, 12761289.

Bruno, F. (2012). Rastros Digitais sob a perspectica da Teoria Atorrede. Revista Famecos, 19(3). Recuperado em 12 de setembro de 2014, de http://revistaseletronicas. pucrs.br/ojs/index. php/revistafameco s/article/view/12893/8601 
Castells, M. (2003). A Galaxia da internet: reflexões sobre a internet, os negócios e a sociedade. Rio de Janeiro: Jorge Zahar Ed.

Jenkins, H. (2008). Cultura da Convergência. São Paulo: Aleph.

Johnson, S. (2003). Emergência: a dinâmica de rede de formigas, cérebros, cidades e softwares. Rio de Janeiro: Jorge Zahar Ed.

Kinder, M. (1991). Playing With Power in Movies, Television, and Video Games: from Muppet Babies to Teenage Mutant Ninja Turtles. Berkeley, California: University of California Press.

Latour, B. (1994). Jamais fomos modernos: ensaio de antropologia simétrica. Rio de Janeiro: Editora 34.

Latour, B. (2000). Ciência em Ação: como seguir cientistas e engenheiros sociedade afora. São Paulo: Editora UNESP.

Latour, B. (2005). Reassembling the Social: a introduction to actornetwork-theory. New York: Oxford University Press.

Lemos, A. (2013a). Espaço, mídia locativa e teoria ator-rede. Galáxia (São Paulo, Online), (25), 52-65.

Lemos, A. (2013b). A comunicação das coisas: Teoria Ator-rede e cibercultura. São Paulo: Annablume.

Lemos, A. (2013b). A comunicação das coisas. Internet das Coisas e Teoria Ator-Rede. Etiquetas de radiofrequência em uniformes escolares na Bahia. in F. Pessoa (Org.). Cyber Arte Cultura. A trama das Redes (pp. 18-47). Seminários Internacionais Museu Vale, ES Museu Vale, Rio de Janeiro.

Lopes, M. I. V. (2011). Uma agenda metodológica para a recepção transmidiática da ficção televisiva. Anais do XX Encontro da Compós, na UFRGS, 2011. Recuperado em 09 de fevereiro, 2014, http: // www.compos.org. br/pagina. php?menu=91\&mmenu $=6 \& g$ $\mathrm{m}=$ int $\& g$ ti $=$ arqul\&ordem $=3 \& g r u p o 1=9 \mathrm{D}$

Recuero, R. (2009). Redes Sociais na Internet. Porto Alegre: Sulina.

Recuero, R. (2012). A Conversação em Rede: comunicação mediada pelo computador e as redes sociais na internet. Porto Alegre: Sulina. Santaella, L., \& Lemos, R. (2010). Redes sociais digitais: a cognição conectiva do Twitter. São Paulo, Paullus.

\section{Endereço para correspondência}

Ana Paula Pereira Coelho

Universidade Federal do Maranhão - UFMA

Departamento de Comunicação Social

Av. dos Portugueses s/n, Centro de Ciências Sociais, Bacanga, CEP 65080-040, São Luís - MA, Brasil

Endereço eletrônico: ana.coelho.jornal@gmail.com

\section{Patrícia Azambuja}

Universidade Federal do Maranhão - UFMA

Departamento de Comunicação Social

Av. dos Portugueses s/n, Centro de Ciências Sociais, Bacanga, CEP 65080-040, São Luís - MA, Brasil

Endereço eletrônico: patriciaazambuja@yahoo.com.br 
Recebido em: 29/05/2014

Reformulado em: 22/09/2014

Aceito para publicação em: 22/09/2014

\section{Notas}

* Graduanda do Curso de Comunicação Social da Universidade Federal do Maranhão

** Professora Adjunta do Curso de Comunicação Social da Universidade Federal do Maranhão. Doutora em Psicologia Social - UERJ e coordenadora do projeto de pesquisa "Comunicação Expandida: entre mudanças de comportamento e possibilidades de novas produções", financiado pela FAPEMA. Pesquisadoracolaboradora da Rede Brasil Conectado (vinculado ao projeto de pesquisa "Jovem e cosumo midiático em tempos de convergência" - CNPq - UFRGS).

1 Disponível no link http://gl.globo.com/tecnologia/noticia/2014/04/vitimas-denude-selfie-e-sexting-na-internet-dobram-no-brasil-diz-ong.html e acessado em 15 de abril de 2014.

2 Disponível no link http://www.safernet.org.br/site/

${ }^{3}$ J ovem brasileira, de 20 anos, que teve imagens suas, em momento íntimo com o namorado, visualizadas em diversas mídias sociais. Obs.: os nomes reais e identidades de nossos informantes foram alterados por versões fictícias, na medida do possível, no sentido de preservar minimamente sua privacidade.

4 “A expressão caixa-preta é usada em cibernética sempre que uma máquina ou um conjunto de comandos se revela complesxo demais" (Latour, 2000, p.14). Há, portanto, relação com fatos ditos incontestáveis, os quais adquirem estabilidade ao conseguirem neutralizar incertezas e controvérsias ao seu redor. Neste caso, a caixa preta está fechada; ficando a cargo de algum tipo de polêmica ou mudança no cenário geral de existência do fato o poder de reabri-la.

${ }^{5}$ De acordo com Bruno Latour, a palavra ator, do inglês actor, se limita a identificar humanos, por isso, muitas vezes utiliza actante (actant), termo emprestado da Semiótica, para incluir não-humanos no entedimento sobre coletivo.

6 Trechos de matéria veiculada em $17 / 11 / 2013$ e disponível no link: http://gl.globo.com/fantastico/noticia/2013/11/nao-tenho-mais-vida-diz-fran-

sobre-video-intimo-compartilhado-na-web.html

${ }^{7}$ Os layouts de todas as páginas originais foram alterados com o objetivo de preservar o anonimato dos participantes.

${ }^{8}$ Chamados de virais ou memes, estão vinculados à cultura da replicação de ideias e estimulam o entendimento em torno da difusão da informação. Ver outros exemplos em Azambuja e Monteiro, 2012.

${ }^{9}$ É o uso das tecnologias digitais de informação para comportamentos de hostilização de indivíduos. A ação consiste no uso do espaço da internet para humilhação pública.

10 Movimento que surgiu a partir de um protesto realizado no ano 2011, em Toronto/ Canadá, e desde então se internacionalizou, sendo realizado em diversas partes do mundo. A Marcha das Vadias protesta contra a crença de que as mulheres que são vítimas de estupro teriam provocado a violência por seu comportamento.

${ }^{11}$ Quando indivíduos se utilizam de imagens íntimas dos parceiros para humilhá-los publicamente em ambiente digital, quase sempre em atos de vingança.

12 Trechos de matéria veiculada em 17/11/2013 e disponível no link: http://gl.globo.com/fantastico/noticia/2013/11/nao-tenho-mais-vida-diz-fransobre-video-intimo-compartilhado-na-web.html 
13 Trechos de matéria veiculada em 23/10/2013 e disponível no link: http://gl.globo.com/goias/noticia/2013/10/nao-me-arrependo-porque-fiz-poramor-diz-garota-sobre-video-de-sexo.html

${ }^{14}$ Lógica de comportamento baseada em referências e estímulos locais. "Vemos comportamentos emergentes em sistemas como os de colônias de formigas, onde os agentes individuais do sistema prestam atenção a seus vizinhos mais próximos em vez de ficarem esperando por ordens superiores. Eles pensam localmente, e agem localmente, mas sua ação coletiva produz comportamento global" (Johnson, 2003, p.54). 